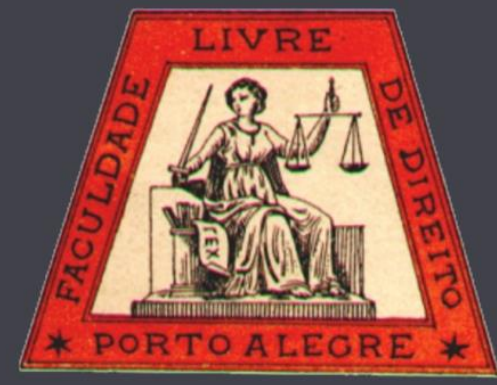

\title{
A substituição indevida da ordem estatal por direitos inoficiais: da inefetividade dos estados sociais à emergência de pluralismos jurídicos questionáveis quanto a sua legitimidade
}

The undue replacement of the State order by unofficial Laws: from the

welfare state ineffectiveness to the expasion of legal pluralisms with doubtful legitimacy

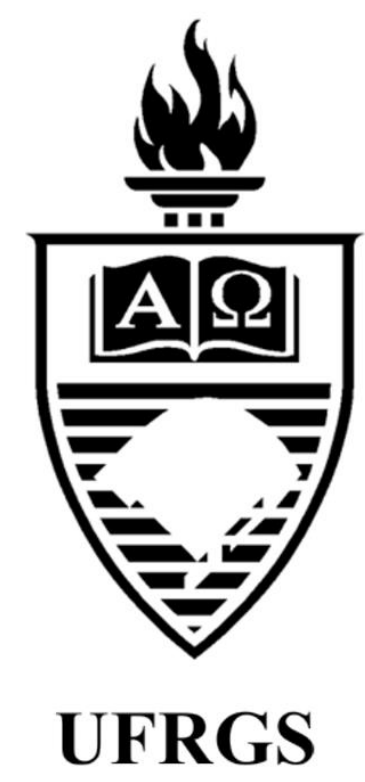

Dezyree Rodrigues da Rosa

Universidade Federal do Rio Grande do Sul

José Alcebíades de Oliveira Junior

Universidade Federal do Rio Grande do Sul 


\title{
A substituição indevida da ordem estatal por direitos inoficiais: da inefetividade dos estados sociais à emergência de pluralismos jurídicos questionáveis quanto a sua legitimidade*
}

\author{
The undue replacement of the State order by unofficial Laws: from the welfare state ineffectiveness to \\ the expasion of legal pluralisms with doubtful legitimacy
}

Dezyree Rodrigues da Rosa**

José Alcebíades de Oliveira Junior ${ }^{* * *}$

\begin{abstract}
REFERÊNCIA
ROSA, Dezyree Rodrigues da; Oliveira Junior, José Alcebíades de. A substituição indevida da ordem estatal por direitos inoficiais: da inefetividade dos estados sociais à emergência de pluralismos jurídicos questionáveis quanto a sua legitimidade. Revista da Faculdade de Direito da UFRGS, Porto Alegre, n. 34, p. 48-65, ago. 2016.
\end{abstract}

\begin{abstract}
RESUMO
A presente pesquisa destina-se a observar, analisar e tentar justificar fatores que levam a substituição do Estado por uma espécie de "direito entre particulares". Esta nova ordem nascida do pluralismo jurídico fornece subsídios que o governo não vem conseguindo conceder e, assim, acaba por fomentar o distanciamento entre estas pessoas e o Estado. Objetiva-se também entender como ou se a insuficiência de assistência em setores básicos como educação, saúde, cultura e outras, que estão elencados no que é entendido como bem-estar social, abre margem para a naturalização e até fomento do crime dentro destas áreas. A fim de delimitar a área de estudo, o trabalho se concentrará em analisar o fenômeno nas áreas de maior vulnerabilidade nos quesitos sociais, educacionais e econômicos, in casu, as favelas.
\end{abstract}

\begin{abstract}
The present research is intended to observe, analyze, and try to justify factors that lead to the substitution of the State for a kind of "Law between private individuals". This new order born out of the legal pluralism provides benefits that the government has not managed to grant, and, thus, in the end promotes the distancing between these people and the State. The objective is also to understand how or if the insufficiency of assistance in basic sectors such as education, health, culture, and others, which are cataloged in what is understood as welfare state, gives margin to the naturalization and even fosters the crime within these areas. In order to delimit the study area, this work will focus on analyzing the phenomenon in the areas of greatest vulnerability in the social, educational, and economic areas, in casu, the slums.
\end{abstract}

\section{PALAVRAS-CHAVE}

\section{KEYWORDS}

\footnotetext{
* O presente artigo é oriundo de Pesquisa Iniciação Cientifica, desenvolvida no ano de 2015 pela graduanda Dezyree Rodrigues da Rosa, sob a orientação do Professor José Alcebíades de Oliveira Júnior. Referida pesquisa foi apresentada no Salão de Iniciação Científica da UFRGS, recebendo o prêmio de Destaque de Iniciação Científica na área de Ciências Sociais aplicadas, na sessão de "Fundamentos Filosóficos e Dogmáticos dos Direitos Humanos e dos Direitos Fundamentais" e o prêmio Jovem Pesquisador UFRGS 2015. Também foi indicada a reapresentação na Jornada Nacional de Iniciação Científica, durante na $68^{\mathrm{a}}$ Reunião Anual da Sociedade Brasileira de Progresso para a Ciência. Por fim, recebeu o Prêmio Destaque de Iniciação Científica e Tecnológica do CNPq, na área de Ciências Humanas e Sociais, honraria à nível nacional que visa promover a Iniciação Científica e incentivar os discentes a ingressar na carreira acadêmica, gratificando seus vencedores com bolsa de mestrado e gratificação pecuniária.

${ }^{* *}$ Graduanda em Direito da Universidade Federal do Rio Grande do Sul e bolsista de Iniciação Científica CNPq. Vencedora dos Prêmios Destaque Nacional de Iniciação Científica e Tecnológica do CNPq, Prêmio Jovem Pesquisadora UFRGS 2015 , Prêmio de Pesquisadora Destaque no Salão de Iniciação Científica da UFRGS nos anos de 2014 e 2015 e vencedora da Competição de Arbitragem em Direito Empresarial (CAEMP) da PUCRS.

*** Orientador de Iniciação Científica da autora e pós-Doutor em Direito pela Justus-Liebig-Universität Giessen, Alemanha. Doutor em Direito pela Universidade Federal de Santa Catarina. Professor Titular da UFRGS.
} 
Pluralismo Jurídico. Direitos Fundamentais. Estado Social. Favelas. Criminalidade. Violência Policial.
Legal Pluralism. Fundamental Rights. Welfare State. Slums. Criminality. Police Violence.

\section{SUMÁRIO}

Introdução. 1. A realidade das favelas e a violação de direitos fundamentais. 2. Análise de casos. 3. Debate entre monismo e pluralismo jurídico e a legitimidade do poder. 4. Os Princípios da Juridicidade (Legality). Considerações finais.

Referências.

\section{INTRODUÇÃO}

Quando nos deparamos com a verdadeira realidade social brasileira, é percebido que a maioria da população sofre com aspectos que vão muito além dos dogmas e teorias do direito constantemente apresentados aos universitários.

Nas salas das Instituições de Ensino jurídico pouco se discute sobre o cotidiano e os problemas enfrentados pelos mais socio-economicamente vulneráveis. Não obstante, será deste núcleo acadêmico que sairão os futuros juízes, promotores, advogados e ministros de nosso país, que por sua vez serão os mesmos que deverão julgar ou representar estas pessoas mais humildes.

Atualmente, em meio à crise de valores enfrentada na política e em outros setores, nos questionamos quanto à justiça, coerência e eficácia dos nossos tribunais, esquecendo que a formação das autoridades é, quase sempre, distante da realidade social e sem grandes problematizações quanto a este assunto. Não é de se surpreender, portanto, que um magistrado que se dedicou por toda carreira ao estudo puro do Direito, não consiga compreender a lógica existente em outras relações que não as jurídicas.

Nesse sentido, a presente pesquisa é movida pelo desejo de desbravar um assunto que vai além do âmbito exclusivamente jurídico. Para tanto, será trabalhado o tema do pluralismo jurídico existente dentro das periferias.
A discussão se concentra em entender como a falta de assistência estatal em setores básicos como educação, saúde, emprego, segurança e outras, que estão elencados no que é entendido como bem-estar social, abre margem para a naturalização e até fomento do crime dentro de regiões marginalizadas.

Conforme o entendimento de Norberto Bobbio $^{1}$, o sistema pela força não é direito. Então, seria o direito legítimo apenas com uma finalidade moral? Se a auctoritas dos traficantes não fosse baseada em atos ilícitos, seria válida essa outra ordem normativa? Procura-se- entender qual a legitimidade do poder do traficante, apreciando os conceitos de pluralismo jurídico, políticas de inclusão, direito favelar etc.

Com o intuito de desenvolver academicamente o assunto, é estabelecido um arcabouço teórico pelo qual a linha de raciocínio segue. Para tratar de pluralismo jurídico são estudados, dentre outros, Eugen Enrlich, Boa Ventura de Souza Santos e Antonio Carlos Volkmer.

Esses conceitos e teorias foram aplicados sobre casos fáticos encontrados por meio de notícias, dados de Organizações Não Governamentais, Relatórios estatais e entrevistas com traficantes e moradores de áreas pobres. Ressalta-se que a intenção ao aplicar um método de pesquisa parcialmente desvinculado de teorias jurídicas sobre Estado e poder, todavia mais aproximado de acontecimentos reais e atuais, é

\footnotetext{
${ }^{1}$ BOBBIO, Norberto. A análise funcional do direito: tendências e problemas. Da Estrutura à Função: Novos Estudos de Teoria do Direito. Barueri: Manole, 2007.
} 
demonstrar o cotidiano das comunidades marginalizadas e visualizá-las pelo mesmo prisma que aqueles dos que lá residem.

Isso pois a população das periferias brasileiras, apesar de historicamente excluída, representa, segundo pesquisa de 2011 do $\mathrm{IBGE}^{2}$, 11,4 milhões de brasileiros. E pelos dados apresentados no relatório de 2006/2007 da ONUHábitat (Programa das Nações Unidas para os Estabelecimentos Humanos) sobre os centros urbanos no mundo, o número de moradores nas favelas brasileiras deve subir para 55 milhões até2020 - o que seria equivalente a $25 \%$ da população do país, de acordo com projeções demográficas feitas pelo IBGE ${ }^{3}$.

A relevância social desse tipo de pesquisa não se refere apenas ao alto número de moradores dessas áreas, mas também por que à medida que essas pessoas se vinculam ao crime, seja como agentes do tráfico ou apenas sendo complacentes com ele, o crime se fortalece e, por conseguinte, aumenta a taxa de violência urbana, problema que atinge a todos. Portanto, é impossível reivindicar cidades mais seguras sem questionar a realidade e as razões da concentração de crimes em determinadas áreas.

Ao longo dos anos, como se demonstra, as favelas se tornaram um cenário marcado pela pobreza e pela criminalidade. Nesse ínterim de exclusão e violência, sem poder contar com o aparato estatal para ordenar sua convivência e solucionar suas lides, os marginalizados procuraram se organizar, formando um

2 CENSO IBGE 2010. Disponível em: < http://www.ibge.gov.br/home/estatistica/populacao/censo2 010/aglomerados_s

ubnormais_informacoes_territoriais/default_informacoes_t erritoriais.shtm>.

${ }^{3}$ Relatório sobre o estado das cidades do mundo 2006/2007. (State of the World's Cities Report 2006/7), lançado o dia 16/06/2006 em Vancouver, Canadá pela UN-HABITAT. microcosmos em que definem suas próprias regras.

Não apresenta novidade tal atitude, haja vista que as necessidades fundamentais, ou seja, aquelas conceituadas como essenciais para a satisfação e realização da vida humana, quando não satisfeitas acabam gerando contradição, conflito, luta e reorganização ${ }^{4}$.

Parece claro que nestas circunstâncias surja uma forma alternativa de direito que vise solucionar as demandas do determinado grupo social. Não obstante, em alguns quesitos, são os traficantes, chamados de "reis do morro" que têm a autoridade para determinar normas, julgar e punir. Eles se aproveitam da lacuna deixada pelo Estado para serem os mantenedores da ordem pública na região. Além de proporcionar assistência comunitária, oferecem segurança, proteção e mediação de conflitos entre os moradores.

Nesse sentido, o presente trabalho se divide em apresentar o cotidiano de violência e violação de direitos das favelas e casos notórios que envolvem a temática. Após, há uma parte homônima com conceitos e teorias que dissertam sobre esta realidade paralela e um teste elaborado com os standarts de Lon Fuller ${ }^{5}$ para analisar o ordenamento estabelecido pelos traficantes e, por último, as conclusões finais.

\section{A REALIDADE DAS FAVELAS E A VIOLAÇÃO DE DIREITOS FUNDAMENTAIS}

Sobre o assunto ler em: <http://www.bbc.com/portuguese/reporterbbc/story/2006/0 6/060616_onu_habitat_novo_is.shtml>.

4 WOLKMER, Antônio Carlos. Pluralismo Jurídico: Fundamentos de uma nova cultura no direito. São Paulo: Editora Alfa Omega, 2001, p. 91.

5 FULLER, Lon. Morality of Law. London: Yale University, 1964. 
A fim de tentar exemplificar os motivos que distanciam o Estado das periferias, apresentamos um breve relato histórico sobre a formação das favelas e alguns direitos constitucionalmente positivados que são diariamente desrespeitados dentro das comunidades.

A exclusão das favelas pelo poder público ocorre desde sua formação, que começou após a vitória na Guerra de Canudos na Bahia. Na época, os soldados do exército, sem receber o devido salário, instalaram-se provisoriamente em alguns morros da cidade, juntamente com outros desabrigados. No período da Proclamação da República, em 1889, os governantes cariocas desejavam extinguir os rastros coloniais ainda existentes na cidade do Rio de Janeiro. Assim, cortiços povoados por escravos libertos foram demolidos para a reforma de Pereira Passos, prefeito do Rio de Janeiro no início do século XX. Os desabrigados foram coagidos a ocupar e construir casas nos entornos urbanos. Em 1900, já estavam ocupados os morros dos Telégrafos e Mangueira ${ }^{6}$.

Estes ambientes também eram denominados "bairros africanos", tendo em vista que esses eram os redutos onde muitos exescravos, sem terra ou pessoas carentes recursos financeiros, iam morar. Em meados do século XX, também se tornaram refúgio de migrantes nordestinos que se deslocaram para as capitais em busca de trabalho, mas que ao se deparar com a

\footnotetext{
${ }^{6}$ FLORA, Flora d'El Rei Lopes. Morro da Mangueira: O samba como (trans)formador da favela. Dissertação de Mestrado em Arquitetura, Universidade Federal de Viçosa, Viçosa, 2008.

${ }^{7}$ PORTAL Afro, 2012. O surgimento das favelas no Brasil. Disponível

<http://portalafrobrasil.blogspot.com.br/2012/10/o-

surgimento-das-favelas-no-brasil.html $>$.

${ }^{8}$ Relatório sobre o estado das cidades do mundo 2006/2007.

(State of the World's Cities Report 2006/7), lançado o dia
}

realidade das metrópoles, que exigem cada vez maiores condições econômicas para habitá-las, se viram obrigados a morar nesses locais. Assim, nutriu-se um ressentimento e um medo por parte da classe média/alta em relação a população negra e pobre que lá habitava.

Ao longo da história das favelas, em razão deste distanciamento imposto pelo restante da sociedade, foi falha a pretensão constitucional de alcance de direito à agua, saneamento básico, educação de qualidade, isonomia, à terra, direito das minorias étnicas, proteção às crianças e segurança face as mais diversas formas de violência, conforme pretende-se demonstrar aqui.

$\mathrm{O}$ documento $\mathrm{O}$ Estado das Cidades do Mundo 2006-2007, elaborado pelo programa ONU-Habitat ${ }^{8}$, mostra como as condições de moradia afetam quem vive na marginalidade: eles passam mais fome, têm menos educação, menos chances de conseguir emprego no setor formal e sofrem mais com doenças que o resto da população das cidades. Ademais, dados do DATAFAVELA, primeiro instituto de pesquisa focado na realidade das favelas brasileiras, revelam que $65 \%$ dos moradores de periferia do Rio têm medo de sofrer violência policial dentro de suas comunidades ${ }^{9}$.

As casas situadas nas áreas periféricas não possuem Registro Público em sua imensa maioria. Por consequência, os moradores não têm respeitados direitos relativos à moradia, como o da inviolabilidade domiciliar. O grande número

16/06/2006 em Vancouver, Canadá pela UN-HABITAT. Sobre o assunto ler em: BBC, 2006. ONU: Brasil terá 55 milhões vivendo em favelas até 2020. Disponível em: <www.bbc.com/portuguese/reporterbbc/story/2006/06/060 616_onu_habitat_novo_is.shtml>.

${ }^{9}$ GLOBO G1, 2015. Violencia policial: $65 \%$ de moradores de favelas do Rio temem, diz estudo. Disponível em: < http://g1.globo.com/rio-de-

janeiro/noticia/2015/06/violencia-policial-65-de-

moradores-de-favelas-do-rio- temem-diz-estudo.html>. 
de despejos ${ }^{10}$ também os torna receosos para clamar ao poder público em eventual momento de necessidade, visto que sua situação irregular pode ser descoberta.

No que tange os direitos sociais, apenas 1,6 $\%$ (CENSO IBGE 2010) dessas pessoas possuem ensino superior completo, $52 \%$ da população não têm coleta de esgoto e somente $38 \%$ deste é tratado, segundo a Relatora especial das Nações Unidas para o direito à água e saneamento ${ }^{11}$. Portanto, direito à educação, saúde, asilo inviolável e dignidade da pessoa humana são postos de lado quando se trata de pessoas marginalizadas.

Ademais, as favelas costumam ser vistas com medo e preconceito e isso se reflete nos altos números de assassinatos que lá ocorrem. A frequente afirmação, socialmente aceita, de que a luta contra a violência urbana justifica todo e qualquer tipo de uso da força estatal, além de ferir direitos fundamentais, abre margem para uma caça dentro das periferias. Esta, somada ao preconceito racial e sócio-econômico resulta naquilo que beira a um genocídio da juventude negra nas favelas do Brasil. Uma análise sobre as informações do perfil das vítimas de homicídio decorrente de intervenção policial revela que elas são majoritariamente jovens, negras, pobres e do sexo masculino ${ }^{12}$.

\footnotetext{
${ }^{10}$ GLOBO G1, 2015. Violência policial: $65 \%$ de moradores de favelas do Rio temem, diz estudo. Disponível em: < http://g1.globo.com/rio-de-

janeiro/noticia/2015/06/violencia-policial-65-demoradores-de-favelas-do-rio- temem-diz-estudo.html>.

11 NAÇÕES UNIDAS, 2013. Apesar de progressos, saneamento é 'sonho distante' para milhões de brasileiros, diz relatora da ONU. Disponível em: $<$ https://nacoesunidas.org/apesar-de-progressossaneamento-e-sonho-distante-para-milhoes-de-brasileirosdiz-relatora-da-onu/>.

12 ALSTON, Phillip. Promoção e proteção de todos os direitos humanos, civis, políticos, econômicos, sociais e
}

Destaca-se aqui operações realizadas pela polícia porque esta é a instituição que personifica o Estado no cotidiano das pessoas e, portanto, reflete a forma com que a população enxerga o aparato estatal. As informações do Relatório "Você matou meu filho! - Homicídios cometidos pela Polícia Militar na cidade do Rio de Janeiro", da Campanha "Jovem Negro Vivo!"13, elaborada pela Anistia Internacional, afirmam que nos últimos 10 anos, foram 8.466 homicídios decorrentes de intervenção policial no Estado do Rio de Janeiro - 5.132 apenas na capital. As mortes decorrentes de intervenção policial, ocasionadas pelo uso desnecessário e excessivo da força, representam uma porcentagem significativa em relação ao total de mortes intencionais violentas na cidade do Rio nos últimos cinco anos - cerca de $16 \%$.

A lógica estatal se demonstra tão truculenta que em 1995 o então governador do estado do Rio de Janeiro, Marcello Alencar, estabeleceu pelo Decreto-Lei 21753/1995 um valor adicional à remuneração de policiais civis e militares, que podia chegar a $150 \%$ do salário, pela realização de atos considerados de bravura, como a morte de um mero suspeito em uma operação policial. Esse adicional ficou conhecido como "gratificação faroeste" e esteve em vigor até 1998, quando foi extinto pela Assembleia Legislativa do Estado do Rio de Janeiro ${ }^{14}$. Pesquisa feita pelo Iser (Instituto

culturais incluindo o direito ao desenvolvimento. Relatório para o Conselho de Direitos Humanos das Nações Unidas, do relator especial de execuções extrajudiciais, sumárias ou arbitrárias, Missão ao Brasil. Tradução: Project on Extrajudicial Executions of the Center for Human Rights and Global Justice, New York University School of Law. Nova York: New York University School of Law, 2008.

13 ANISTIA Internacional. Você matou meu filho!: homicídios cometidos pela polícia militar do Rio de Janeiro. Brasil: Anistia Internacional, 2015.

${ }^{14}$ Idem, p. 24. 
de Estudos da Religião) e pela Alerj ${ }^{15}$ concluiu que antes da instituição da gratificação, a taxa de letalidade era de dois mortos para cada operação policial que ocorria em confrontos entre policiais e civis e após, dobrou quatro mortos e um ferido.

A impunidade dos policiais que agem de forma abrupta e ilegal é alta. Dos 220 registros de homicídios decorrentes da violência policial na cidade do Rio de Janeiro em 2011, até abril de 2015 apenas uma denúncia havia sido feita por parte do Ministério Público contra os policiais envolvidos e $83 \%$ das investigações ainda não tinham sido concluídas ${ }^{16}$. Apenas uma investigação imparcial e independente pode dizer se, em cada um dos casos, o uso da força foi legítimo, houve abusos por parte dos policiais ou se há indícios de execuções. O relatório do Relator Especial das Nações Unidas denuncia a quantidade exorbitante de execuções extrajudiciais sumárias ou arbitrárias por policiais em serviço ou fora dele (esquadrões da morte, grupos de extermínio e milícias), bem como execuções extrajudiciais no sistema prisional ${ }^{17}$.

\section{O "Caso Amarildo", que ficou} nacionalmente conhecido, é mais um dos exemplos do porquê os moradores de baixa renda sentirem-se reprimidos ao procurar o aparato estatal para resolver seus litígios. Amarildo era um pedreiro que foi levado de sua casa por

\footnotetext{
${ }^{15}$ Relatório Letalidade da Ação Policial no Rio, do Instituto de Estudos da Religião (Iser). Ler mais sobre em: $<$ http://alerjln1.alerj.rj.gov.br/scpro1115.nsf/1061f759d97a 6b24832566ec0018d832/4de27c9e38506f18832

57920006711c7? OpenDocument\&ExpandSection=-1>.

16 ANISTIA Internacional. Você matou meu filho!: homicídios cometidos pela polícia militar do Rio de Janeiro. Brasil: Anistia Internacional, 2015.

17 ANISTIA Internacional. Você matou meu filho!: homicídios cometidos pela polícia militar do Rio de Janeiro. Brasil: Anistia Internacional, 2015.

18 ANISTIA Internacional. Você matou meu filho!: homicídios cometidos pela polícia militar do Rio de Janeiro. Brasil: Anistia Internacional, 2015.
}

policiais da UPP da Rocinha em julho de 2013. Ele foi torturado, morto e seu corpo ainda está desaparecido. As investigações indicaram que mais de 20 policiais e inclusive o comandante da UPP está envolvido no caso ${ }^{18}$.

No mais, conforme já alertava Boa Ventura de Souza Santos ao visitar a favela do Jacarézinho no distante ano de 1970, mesmo que se intencionasse e chamar a polícia, isso não aconteceria pois ela era mal vista pelos moradores por somente aparecer naqueles locais para executar ordens de despejo ou procurar suspeitos de cometer crimes. Ainda, mesmo se fosse chamada, haveria o desmazelo e o temor de como seria recebida. E ainda que algum morador efetuasse o chamado, seria tomado pelos demais como traidor, podendo vir a ser expulso da comunidade ${ }^{19}$.

O mesmo distanciamento ocorre quanto ao Judiciário, ainda que por diferentes motivos. "Juízes e advogados eram vistos como demasiado distanciados das classes baixas para poder entender as necessidades e aspirações dos pobres"20. Outrossim, os honorários advocatícios usualmente cobrados não respondiam à capacidade econômica dos moradores e, cientes da sua situação irregular de moradia ${ }^{21}$, "recorrer aos tribunais para resolver conflitos sobre terras e habitações só era inútil como perigoso" 22 .

19 KONZEN, Lucas Pizzolatto. Boas aventuras na Pasárgada do pluralismo jurídico ou alternativas para uma ciência do direito pós-moderna? Prisma Jurídico, São Paulo. v. 5, p. 169-184, 2006, p. 175.

20 SANTOS, Boaventura de Sousa. Uma cartografia simbólica das representações sociais. Revista Crítica de Ciências Sociais, n. 24, p. 139-172, 1988, p. 91.

21 KONZEN, Lucas Pizzolatto. Boas aventuras na Pasárgada do pluralismo jurídico ou alternativas para uma ciência do direito pós-moderna? Prisma Jurídico, São Paulo. v. 5, p. 169-184, 2006.

22 SANTOS, Boaventura de Sousa. Uma cartografia simbólica das representações sociais. Revista Crítica de Ciências Sociais, n. 24, p. 139-172, 1988. 
Ademais, todo o formalismo, linguagem neutra e impessoal, trajes majestosos, distância do magistrado no tribunal, universalidade das decisões e outras formas de violência simbólicas intrínsecas ao mundo jurídico tornam o Judiciário assustador e enigmático aos que são pertencentes a classes menos favorecidas ${ }^{23}$.

\section{ANÁLISE DE CASOS}

Este trabalho teve como leading case de pluralismo jurídico a morte do traficante Alexandre Goulart Madeira, popularmente conhecido como Xandi, morto por integrantes de uma gangue rival em janeiro de 2015. Ele recebeu como homenagem póstuma uma música de funk de um cantor adolescente e uma grafitagem de pelo menos $60 \mathrm{~m}^{2}$ em uma das paredes do Condomínio Princesa Isabel, na Zona Leste de Porto Alegre, comunidade em que traficava desde a última década. Desperta a atenção o fato de a pintura ter custado cerca de 10 mil reais, e este montante, segundo os próprios moradores, ter sido rateado entre eles. Segundo a presidente da Associação dos Moradores do Condomínio, Xandi era adorado por todos que vivem no prédio. Sustenta que o traficante auxiliava a comunidade sempre que preciso, patrocinando o funcionamento das creches, fornecendo festas, cedendo empréstimos ou distribuindo remédios para os enfermos ${ }^{24}$.

$\mathrm{O}$ fato não é novidade, um dos narcotraficantes mais famosos do América Latina,

\footnotetext{
${ }^{23}$ BOURDIEU, Pierre. O poder simbólico. Tradução de Fernando Tomaz. $5^{\text {a }}$ ed. Rio de Janeiro: Bertrand Brasil, 2002, p. 209-254.

${ }^{24}$ ZERO Hora, 2015. Chefe do crime e benfeitor: as duas faces de Xandi. Disponível em < http://zh.clicrbs.com.br/rs/noticia/2015/03/chefe-do-crimee-benfeitor-as-duas-faces-de-xandi-4712630.html $>$.
}

Pablo Escobar, nos anos 80, também já era conhecido como

"Padrinho" e adorado pelos moradores. Playboy, um dos traficantes mais procurados do Rio de Janeiro, confirma em entrevista que na sua comunidade, como nas demais, era proibido andar com carros roubados, assaltar dentro das comunidades, usar crack ou participar brigas nas ruas, o que satisfazia a população ${ }^{25}$.

Apelidado de "Nem", Antônio Bonfim Lopes foi o comandante do tráfico na favela da Rocinha no início dos anos 2000. Ele acreditava que o dono do morro deveria criar um círculo virtuoso que assegurasse o sustento da favela, devolvendo parte dos lucros à comunidade e criando um clima de crescimento econômico. Sob o seu comando era vedado ameaças aos moradores, adolescentes não podiam ingressar no mundo do crime e a comercialização do crack é proibida. "Durante seu período no poder, Nem constrói um campinho de futebol para a comunidade, paga viagens de moradores ao Nordeste para reverem a família, banca tratamentos médicos e providencia cestas básicas para os mais carentes". "Não era uma democracia", admite Nem. "Mas ao mesmo tempo não era uma ditadura, porque eu sempre explicava meu raciocínio aos moradores". Estima-se que o lucro mensal da quadrilha de Nem era de 10 a 15 milhões de reais mensais ${ }^{26}$.

Não obstante, junto aos benefícios fornecidos pelos comandantes da periferia, há os tribunais do tráfico. Nesses, segundo relatos de

25 NOTÍCIAS R7 Record, 2011. Crimes proibidos por "leis" do tráfico afligem favelas pacificadas do Rio. Disponível em: <http://noticias.r7.com/rio-dejaneiro/noticias/crimes-proibidos-por-leis-do- traficoafligem-favelas-pacificadas-do-rio-20111009.html>.

${ }^{26}$ GLENNY, Misha. O Dono do Morro: Um homem e a batalha pelo Rio. Tradução: Denise Bottman. 1a ed. São Paulo: Companhia das Letras, 2016. 
moradores e traficantes, todas as normas são ordenadas segundo o arbítrio dos traficantes e os réus são condenados conforme a sua determinação. Os suspeitos de roubo de moradores, crimes sexuais e contra a vida são prontamente sentenciados à morte. Existem também penas "mais brandas", como por exemplo, agressão física, tiro na mão, expulsão da comunidade e raspagem do cabelo de mulheres que se envolvem com homens casados ou brigam em bailes funk, por exemplo ${ }^{27}$.

Aparentemente, pode parecer absurdo que os moradores das comunidades admitam submeter-se às leis do tráfico. Entretanto, é preciso atentar paras as necessidades humanas. Em meio ao terror e ao caos, o ser humano se torna mais suscetível a estes tipos submissão. Foi o que houve no início do totalitarismo na Alemanha, que contou com apoio popular. Ou até mesmo hoje que, em meio à crise políticoeconômica, certas pessoas clamam pelo retorno da ditadura militar pelo simples fato acreditarem que essa é a única forma de encontrar segurança, estabilidade e progresso.

E, como já dito anteriormente, os residentes dessas áreas vulneráveis não possuem mais confiança no poder estatal. O relato de uma moradora da Favela da Rocinha, no Rio de Janeiro, concedida ao Jornal do Brasil, descreve bem a situação atual e expõe um dado surpreendente: houve piora na violência desde a pacificação e há falta de representatividade da Unidade de Polícia Pacificadora (UPP) entre os

\footnotetext{
${ }^{27}$ REVISTA Marie Claire, 2012. Cabeças marcadas pelo tráfico: "código penal" de algumas favelas cariocas castiga mulheres raspando seus cabelos. Disponível em: $<$ http://revistamarieclaire.globo.com/Revista/Common/0, EMI313737-17737-1,00-

CABECAS+MARCADAS+PELO+TRAFICO+CODIGO

+ PENAL+DE+ALGUMAS

+FAVELAS+CARIOCAS+CAST.html>.
}

habitantes da comunidade. Ela afirma: "A violência piorou nos últimos tempos, estão havendo muitos assaltos e arrombamento de casas. Às vezes as pessoas nem vão na UPP denunciar, porque não acreditam que possa resolver. Quando os policiais chegam, tratam mal o morador, falam sem educação ou não ajudam durante uma necessidade, começam a ser mal vistos pelos moradores. Mas não pode criticar só os policiais, o governo poderia instruí-los para agirem melhor", complementa ${ }^{28}$.

Destarte, a questão é entender até que ponto é maléfico para os moradores das comunidades viver sob o comando das leis do tráfico se estas cumprem o objetivo de manter a ordem e a segurança de locais que foram esquecidos pelo governo.

\section{DEBATE ENTRE MONISMO E}

\section{PLURALISMO JURÍDICO E A LEGITIMIDADE DO PODER}

A dualidade existente entre as realidades dos centros da cidade e as periferias, e como ambas encontram maneiras tão distintas de resolver seus litígios, levanta a questão de monismo versus pluralismo jurídico.

O monismo jurídico, resumidamente, é aquele que compreende o ordenamento positivado, ou seja, as leis feitas pelo Estado sendo a única fonte de Direito correta e válida ${ }^{29}$. Thomas Hobbes, um dos escritores que concretiza tal teoria, doutrina que "todas as leis, escritas ou

28 JORNAL do Brasil, 2014. UPP: uma política de 'adestramento' que deixa de lado a integração. Disponível em: $\quad<$ http://www.jb.com.br/rio/noticias/2014/06/14/uppuma-politica-de-adestramento-que-deixa-de-lado-aintegracao/>.

29 WOLKMER, Antônio Carlos. Pluralismo Jurídico: Fundamentos de uma nova cultura no direito. São Paulo: Editora Alfa Omega, 2001, p. 46. 
não recebem toda sua força e autoridade da vontade do Estado"30, bem como "ninguém pode fazer leis a não ser o Estado, pois nossa sujeição é unicamente para com o Estado". Seria, portanto, o ente estatal o único legitimado a produzir normas que regulem as relações sociais e as condutas pessoais.

Tais normas, legisladas e julgadas pelos atribuídos (Poderes Legislativo e Executivo, respectivamente) recebem legitimidade não pela aceitação espontânea dos indivíduos, e sim por terem sido feitas em conformidade com os mecanismos processuais oficiais do poder público, passando a ideia de uma "obediência moralmente motivada" ${ }^{31}$.

Por outro lado, o pluralismo jurídico, reconhece e legitima normas extras e infra estatais, surgidas em face a necessidades existenciais, materiais e culturais que não são supridas pela forma de poder formalmente estabelecida. Este conceito admite que o Estado não é a única manifestação de poder, tampouco a fonte exclusiva de toda produção de Direito, superando as concepções positivistas. Apresenta, assim, a ideia de uma pluralidade jurídica aberta, flexível, participativa e democrática, que se propõe a atender os interesses cotidianos, individuais e coletivos ${ }^{32}$.

Conforme entendimento de Eugen Ehrlich, o direito seria como um produto espontâneo da

\footnotetext{
${ }^{30}$ HOBBES, Thomas. Leviatã ou matéria, forma e poder de um estado eclesiástico e civil. $3^{\mathrm{a}}$ ed. São Paulo: Abril Cultural, 1983, p. 171.

31 WOLKMER, Antônio Carlos. Pluralismo Jurídico: Fundamentos de uma nova cultura no direito. São Paulo: Editora Alfa Omega, 2001, p. 48.

32 WOLKMER, Antonio Carlos. Pluralismo jurídico: nuevo marco emancipatorio en América Latina. Disponible em: < http://bibliotecavirtual.clacso.org.ar/ar/libros/derecho/wolk .rtf>. P. 03-08.

${ }^{33}$ EHRLICH, Eugen. "O conceito prático de direito" $e$ " $A$ coação social e a coerção estatal”. Fundamentos da
}

sociedade. As associações ou organizações humanas criam internamente e de forma natural uma ordem jurídica própria, como a família ou um grupo de amigos, que tem hábitos e normas de convivência particulares e que não dependem da confirmação estatal. Para este autor, estas relações revelam a verdadeira forma do direito ${ }^{33}$.

Antonio Carlos Wolmer ressalta que em países de origem colonial como o nosso houve a imposição de aceitar as normas jurídicas vindas das metrópoles. Esta ruptura de sistema, fez que coexistissem o "Derecho del Estado colonizador $y$ de los Derechos tradicionales" ${ }^{34}$, já dando margem a um pluralismo legal desde a formação do país.

O autor defende que o verdadeiro direito é o direito vivo, que não se prende a doutrinas, dogmas ou prescrições estatais, pois este domina a vida originária e realista ${ }^{35}$. Ele entende a função do direito como de ordem pacífica que deve servir a qualquer associação interna. Para o autor, a legitimação do poder surge não por medo ou submissão, e sim porque os agentes reconhecem tal autoridade como boa e justa. A eficácia do pluralismo ocorre pela satisfação das necessidades e reivindicações do povo. Até porque, nas palavras de Gurvitch, direito não se confunde com estado e pelas ideias de Hanna Arendt, as leis não se confundem com a justiça ${ }^{36}$.

Sociologia do Direito. Tradução de René Ernani Gertz. Brasília: Editora Universidade de Brasília, p. 27.

${ }^{34}$ WOLKMER, Antonio Carlos. Pluralismo jurídico: nuevo marco emancipatorio en América Latina. Disponible em: < http://bibliotecavirtual.clacso.org.ar/ar/libros/derecho/wolk $. r t f>$.

35 WOLKMER, Antônio Carlos. Pluralismo Jurídico: Fundamentos de uma nova cultura no direito. São Paulo: Editora Alfa Omega, 2001.

36 ARENDT, Hannah. As Origens do Totalitarismo. Ideologia e Terror. São Paulo: Companhia das Letras, 1989 
Portanto, a intenção do pluralismo não é negar ou minimizar o Direito Estatal, mas reconhecer a existência de outras fontes de Direito. Seria então o direito um fato social em constante transformação, um direito vivo. Para esta teoria uma das atribuições do Estado seria positivar o Direito, ou seja, transformar o direito natural, consuetudinário e outros que sejam latentes na ordem estatal em normas jurídicas ${ }^{37}$.

Não apresenta novidade o fenômeno do pluralismo, pois sempre houve uma forma de governança que fugisse do controle estatal. Contudo, merece destaque o que ora ocorre nas favelas por se tratar de uma área que tem propensão a abrigar $25 \%$ da população brasileira $^{38}$, necessitando de uma atenção especial para que a sociedade como um todo venha a poder conviver harmoniosamente.

E a realidade atual destas áreas em muito diverge daquela apresentada por Boa Ventura de Souza Santos em sua estadia em Pasárgada. Atualmente, estabeleceu-se um ordenamento próprio dentro das comunidades coordenado por traficantes e que conta com sanções positivas e negativas, normas e julgadores ${ }^{39}$.

Este tipo de situação é comum pelos que lá habitam, e vem se tornando consuetudinária e favorável, devido a desconfiança da população com o poder público e a eficácia dos criminosos para resolver lides cotidianas.

Contudo, é importante destacar que para a autoridade e sucesso nos negócios do criminoso perdurarem, ele precisa manter a confiança e o apoio desse contingente populacional, como todo

\footnotetext{
${ }^{37}$ GUANABARA, Ricardo. Visões alternativas do direito no Brasil. Estudos Históricos, São Paulo, v. 9, n. 18, p. 403416, 1996

${ }^{38}$ Vide citação 02.

${ }^{39}$ BURGOS, Marcelo Baumann; PEREIRA, Luiz Fernando Almeida; CAVALCANTI, Mariana; BRUN, Mario; AMOROSO, Mauro. O Efeito UPP na Percepção dos
}

déspota. O que diferencia a autoridade do traficante daquela de um agente estatal é o tipo de legitimidade do comando do primeiro, que conta com traços de poder carismático e tradicional, pelo conceito weberiano ${ }^{40}$. Este mesmo autor já discutia a legitimidade fundamentada na religião, tradição, carisma e emoção.

E é por isso que as comunidades, sempre que preciso, recebem auxílio, lazer e segurança. Se este "carisma" acaba, o apoio popular também se esvai. Logo, o líder deve demonstrar suas qualidades constantemente, visto que uma falha nessa prova leva a diminuição de sua autoridade e falência nos negócios. Pois, a partir do momento que os residentes das áreas marginalizadas clamarem pela polícia para resolver seus problemas e a mesma atuar no morro de forma digna e eficaz, o tráfico de drogas é prejudicado e a confiança no Estado aos poucos vai se reestabelecendo. A relação do traficante com essas pessoas assemelha-se, mutatis mutandis, ao Contrato Social, mas neste as pessoas compactuam com o crime e reconhecem o transgressor e suas normas como autoridades em troca de poder ter direito a um bairro com normas, segurança e assistência.

\section{OS PRINCÍPIOS DA JURIDICIDADE (LEGALITY)}

Ainda que seja aceita uma concepção pluralista de Direito, esta também deve observar critério de objetividade, respeito, justificação e

Moradores das Favelas. Desigualdade \& Diversidade Revista de Ciências Sociais da PUC-Rio, Rio de Janeiro, $\mathrm{n}^{\circ}$ 11, p. 49-98, ago.-dez., 2011. Disponível em: $<$ http://desigualdadediversidade.soc.pucrio.br/media/4artigo11.pdf $>$.

40 WEBER, Max. Três tipos puros de poder legítimo. Lisboa: Tribuna de História, 2005. 
poder, que são comuns a todas as formas de governo legítimo.

Lon Fuller, um dos maiores teóricos do Direito norte-americanos do século XX, apresenta em sua obra "Morality of Law", oito standards que seriam os pressupostos de uma correta construção da ordem legal em qualquer que seja o sistema em vigor.

\begin{abstract}
Em quase todas as sociedades os seres humanos tornam-se conscientes da necessidade de sujeitar certas condutas ao explícito controle de regras. Quando ingressam neste empreendimento (...), eles descobrem que este (...) possui uma lógica interna própria, que essa estabelece exigências que devem ser satisfeitas (...). É porque os homens geralmente percebem estas exigências e lhes respeitam, que os sistemas jurídicos mostram uma certa semelhança em sociedades que são totalmente diversas. É porque o direito é um empreendimento com um propósito, que ele mostra constantes estruturais que o teórico do direito pode descobrir e tratar como uniformidades que estão dadas factualmente ${ }^{41}$.
\end{abstract}

O raciocínio do autor foi escolhido, apesar das opiniões contrárias vindas de outros filósofos jurídico-positivistas, para analisar as leis do tráfico e a legitimidade do poder dos traficantes. Isso pois, ele apresenta uma abordagem inovadora que se afasta do moralismo tradicional, e é exatamente isto que a presente pesquisa propõe. $\mathrm{Na}$ visão de Fuller, a validade do Direito depende da qualidade do seu conteúdo e não apenas do autoritarismo de sua fonte.

Assim, explicaremos brevemente cada um dos princípios a fim de verificar quais deles são respeitados pelas leis do tráfico. Cabe ressaltar que a intenção não é, de forma alguma, afirmar algum tipo de legalidade nessa relação. Apenas

41 FULLER, Lon. Morality of Law. London: Yale University, 1964, p. 196. desejamos analisar a validade desta ordem normativa peculiar a partir da premissa que todo ordenamento deve ser justo e incorporado aos membros da comunidade. São eles ${ }^{42}$ :

a) Generalidade: $\mathrm{O}$ controle das ações dos cidadãos deve ser feito não por comandos concretos, mas por regras gerais. Esta é a expressão do princípio de que casos iguais devem receber tratamento igual. Estabelece-se aqui o princípio da igualdade (tratar a todos segundo as mesmas regras), conceito de lei próprio do Estado de Direito. A norma necessita ser geral, pois ante um comando particular não há igualdade alguma;

b) Promulgação: Para que a lei passe a ter força, é preciso que ela seja conhecida por aqueles que a irão executar. Isso deve ocorrer por sinais suficientes que permitam a emissão do comando. $\mathrm{Ou}$ seja, a lei deve ser pré-estabelecida e divulgada para que crie força de obrigar;

c) Prospectividade: Muito popular no direito penal, é expressa pela máxima latina nulla poena sine lege. A essência desta máxima é que a lei deve ter existido como norma geral antes de se apresentar o caso ao qual tem de ser aplicada. Isto posto, uma lei positiva não pode ser conhecida antes de ser feita e, portanto, não pode ser obrigatória;

d). Possibilidade: A lei emanada deve contar com um comando que seja possível segundo as limitações naturais do ser, bem como pelo costume humano, pois o homem não pode viver sozinho na sociedade;

e). Clareza: Ser suficientemente clara para alcançar o duplo objetivo de dar ao cidadão uma informação acerca da conduta proibida, e de fornecer adequadas diretivas para as decisões judiciais;

42 FULLER, Lon. Morality of Law. London: Yale University, 1964. 
f). Consistência: Não declarar um ato dotado de ambiguidade sobre o que é lícito ou ilícito.

g) Estabilidade: As regras não devem ser mudadas frequentemente, pois isso diminui sua força coercitiva, enquanto se abole os costumes;

h) Congruência: $O$ último e mais importante princípio determina que, conforme já entendido nas Decretais de Gregório IX, "Todo aquele que estabelece um direito para outro, deve usar o mesmo direito" e diz a autoridade do Sábio: "Sujeita-te à lei que tu mesmo estabeleceste".

Desse modo, ainda que sejam desconsideradas as atividades ilícitas dos traficantes e se passe a considerar apenas os (não poucos) privilégios que eles concedem para as comunidades, este tipo de relação não se configura com um bom ordenamento social.

As leis do tráfico estão sob o alvedrio daquele que comanda as atividades ilícitas no morro, não há segurança jurídica alguma, tampouco formas de recorrer, logo, a prospectividade pode ser desrespeitada a qualquer momento, bem como a congruência. Outrossim, se uma nova facção criminosa toma o poder, todas as leis podem sofrer alteração, e isso ocorre de um dia para o outro, ferindo assim, a estabilidade. No mais, os princípios da generalidade e da congruência são violados porque aqueles que cercam os traficantes e eles próprios não recebem sanções da mesma forma que um morador comum.

Por outro lado, ainda que não de forma escrita, as normas chegam ao conhecimento da população de maneira informal. Todas as que foram encontradas durante este estudo eram claras, consistentes e possíveis.

\section{CONSIDERAÇÕES FINAIS}

Compreende-se a relevância dos pluralismos jurídicos por crer que seu propósito é atingir institutos verdadeiramente democráticos que satisfaçam as necessidades populares, reconhecendo os valores coletivos de cada segmento social. Outrossim, a sociedade atual, complexa e conflitiva, e seus institutos estatais falidos necessitam de uma reinvenção das formas de poder, haja vista a que o atual modelo juspolítico não satisfaz as reinvindicações populares de segurança, representação, ética e justiça.

Não obstante, o que acontece nas favelas, sob as leis do tráfico, não corresponde a uma participação consciente, democrática, pluralista e ativa dos agentes envolvidos. $\mathrm{E}$ isso contraria a noção de justiça, que abarca as expressões de liberdade e igualdade.

À vista disso, entende-se que este tipo de lei em especial não é válido como um bom ordenamento. Pois, além de reprovar nos princípios de Lon Fuller, o poder é despótico, arbitrário e fere os direitos fundamentais sociais tão arduamente conquistados.

O maior risco dos pluralismos jurídicos, ainda que sua proposta seja bem-intencionada, é a perda as garantias já alcançadas. E é exatamente o que aqui se demonstra. $\mathrm{Na}$ ordem imposta pelo criminoso não existem aqueles que são dois dos nossos maiores garantidores de justiça: os princípios processuais e os direitos sociais. Nestes estão inclusos o segundo grau de jurisdição, vedação de pena de morte, direito ao contraditório, presunção de inocência e imparcialidade do julgador- exatamente o contrário do que ocorre nas leis do tráfico.

Ademais, deve ser de extrema preocupação da sociedade que criminosos sejam vistos como heróis. Isso influencia crianças e adolescente a 
adentrar no mundo do crime, aumenta os lucros do tráfico, gera mais viciados em drogas, piora a violência urbana e instiga ainda mais ódio, mortes, medo e preconceito.

Esse tipo de comando secundário nasce por meio da falência daquele que deveria estar cumprindo sua função social, ou seja, o Estado. Depreende-se que a exclusão do poder público para com essas comunidades é um dos maiores fomentadores da manutenção do crime nas periferias. Isso pois, os moradores sujeitam-se aos traficantes com intuito de obter condições de vida mais adequadas, seguras e representativas.

Uma possível solução para esta questão é que se estabeleça uma relação de interação, respeito e confiança entre Estado e favela para que não seja preciso que os moradores de lá recorreram a meios alternativos.

Como foi aqui demonstrado, os habitantes destes locais possuem diversos motivos para não crer e, até mesmo, repudiar os órgãos governamentais. Portanto, essa reconciliação precisa transcender a retomada policial das áreas de risco e instalações de UPPs. Adriana Pirozzi, gestora social e liderança da Rocinha contou ao Jornal do Brasil: "Foi uma pacificação excludente, não tem a parte social. (...)a própria polícia da UPP realiza algumas atividades esportivas para a comunidade, mas que, em geral, não há incentivos". Ela defende que a falta de incentivo social atrapalha o resgate de jovens imersos no tráfico. "O jovem tem que ter oportunidades. Se elas não aparecem, não há como resgatá-lo, na maioria das vezes. Alguns até são resgatados por ONGs que fazem trabalhos isolados, mas é um processo muito lento. Não houve uma intervenção social concreta e a gente sabe que existem verbas para isso". Fabiana Rodrigues, outra liderança da comunidade e criadora do portal "Rocinha em foco", também reclama da falta de apoio". O governo poderia ser mais participativo, trazer mais projetos para as crianças de rua", aponta. 45

Diante do exposto, acredita-se que é responsabilidade do Estado brasileiro e de suas instituições conceder os direitos positivados na Constituição Federal para todos, não apenas moradores de bairros nobres. Portanto, é preciso efetivar aquilo que pretende o Estado Social. É crucial a implementação de políticas inclusivas, que forneçam hospitais, escolas públicas de qualidade, centros poliesportivos e culturais que viabilizem a base necessária para que estas pessoas possam sair da marginalidade e se desenvolver com a dignidade e as condições necessárias a qualquer ser humano.

\section{REFERÊNCIAS}

ALSTON, Phillip. Promoção e proteção de todos os direitos humanos, civis, politicos, econômicos, sociais e culturais incluindo o direito ao desenvolvimento. Relatório para o Conselho de Direitos Humanos das Nações Unidas, do relator especial de execuções extrajudiciais, sumárias ou arbitrárias, Missão ao Brasil. Tradução: Project on Extrajudicial Executions of the Center for Human Rights and Global Justice, New York University School of Law. Nova York: New York University School of Law, 2008. 
ANISTIA Internacional. Você matou meu filho!: homicídios cometidos pela polícia militar do Rio de Janeiro. Brasil: Anistia Internacional, 2015.

ARENDT, Hannah. As Origens do Totalitarismo. Ideologia e Terror. São Paulo: Companhia das Letras, 1989.

BBC, 2006. ONU: Brasil terá 55 milhões vivendo em favelas até 2020. Disponível em: $<$ www.bbc.com/portuguese/reporterbbc/story/2006/06/060616_onu_habitat_novo_is.shtml $>$.

BOBBIO, Norberto. A análise funcional do direito: tendências e problemas. Da Estrutura à Função: Novos Estudos de Teoria do Direito. Barueri: Manole, 2007.

BOURDIEU, Pierre. O poder simbólico. Tradução de Fernando Tomaz. $5^{\mathrm{a}}$ ed. Rio de Janeiro: Bertrand Brasil, 2002.

BRASIL. Constituição (1988). Constituição da República Federativa do Brasil. Brasília: Senado Federal; Centro Gráfico, 1988.

BURGOS, Marcelo Baumann; PEREIRA, Luiz Fernando Almeida; CAVALCANTI, Mariana; BRUN, Mario; AMOROSO, Mauro. O Efeito UPP na Percepção dos Moradores das Favelas. Desigualdade \& Diversidade - Revista de Ciências Sociais da PUC-Rio, Rio de Janeiro, nº 11, p. 49-98, ago.-dez., 2011. Disponível em: $<$ http://desigualdadediversidade.soc.puc-rio.br/media/4artigo11.pdf $>$.
CENSO
$I B G E$
2010.
Disponível
em:

http://www.ibge.gov.br/home/estatistica/populacao/censo2010/aglomerados_s

ubnormais_informacoes_territoriais/default_informacoes_territoriais.shtm $>$.

DATAFAVELA, 2013: Quase 30\% dos moradores de favelas já se sentiram discriminados, diz pesquisa. Disponível em: <http://datafavela.com.br/quase-30-dos-moradores-de-favelas-ja-sesentiram- discriminados-diz-pesquisa/ $>$.

EHRLICH, Eugen. "O conceito prático de direito" e "A coação social e a coerção estatal". Fundamentos da Sociologia do Direito. Tradução de René Ernani Gertz. Brasília: Editora Universidade de Brasília.

FLORA, Flora d'El Rei Lopes. Morro da Mangueira: O samba como (trans)formador da favela. Dissertação de Mestrado em Arquitetura, Universidade Federal de Viçosa, Viçosa, 2008.

FULLER, Lon. Morality of Law. London: Yale University, 1964.

GLENNY, Misha. O Dono do Morro: Um homem e a batalha pelo Rio. Tradução: Denise Bottman. 1a ed. São Paulo: Companhia das Letras, 2016. 
GLOBO G1, 2015. Guardei muitas lembranças, diz filho de Pablo Escobar de infância com o pai. Disponível em: <http:/g1.globo.com/fantastico/noticia/2015/06/guardei-muitas-lembrancas-diz-filhode-pablo-escobar-de-infancia-com-pai.html $>$.

GLOBO G1, 2015. Violência policial: 65\% de moradores de favelas do Rio temem, diz estudo. Disponível em: < http:/g1.globo.com/rio-de- janeiro/noticia/2015/06/violencia-policial-65-demoradores-de-favelas-do-rio- temem-diz-estudo.html $>$.

GUANABARA, Ricardo. Visões alternativas do direito no Brasil. Estudos Históricos, São Paulo, v. 9, n. 18, p. 403-416, 1996.

HAWKINS, W. Steven A polícia brasileira é rápida no gatilho. Disponível em: $<$ https://anistia.org.br/policia-brasileira-e-rapida-gatilho/>.

HAYEK, Frederich August. Direito, Legislação e Liberdade: A ordem política de um povo livre!. São Paulo: Editora Visão LTDA, 1979.

HOBBES, Thomas. Leviatã ou matéria, forma e poder de um estado eclesiástico e civil. $3^{\mathrm{a}}$ ed. São Paulo: Abril Cultural, 1983.

JORNAL do Brasil, 2014. UPP: uma política de 'adestramento' que deixa de lado a integração. Disponível em: <http://www.jb.com.br/rio/noticias/2014/06/14/upp-uma-politica-de-adestramentoque-deixa-de-lado-a-integracao/>.

KONZEN, Lucas Pizzolatto. Boas aventuras na Pasárgada do pluralismo jurídico ou alternativas para uma ciência do direito pós-moderna? Prisma Jurídico, São Paulo. v. 5, p. 169-184, 2006.

MAGALHÃES, Alex. O Direito das favelas no contexto das políticas de regularização: a complexa convivência entre legalidade, norma comunitária e arbítrio. Revista Brasileira de Estudos Urbanos e Regionais, São Paulo, v. 11, n. 01, p. 89-103, 2009.

NAÇÕES UNIDAS, 2013. Apesar de progressos, saneamento é 'sonho distante' para milhões de brasileiros, diz relatora da ONU. Disponível em: < https://nacoesunidas.org/apesar-de-progressossaneamento-e-sonho-distante-para-milhoes-de-brasileiros-diz-relatora-da-onu/>.

NOTÍCIAS R7 Record, 2011. Crimes proibidos por "leis" do tráfico afligem favelas pacificadas do Rio. Disponível em: <http://noticias.r7.com/rio-de-janeiro/noticias/crimes-proibidos-por-leis-dotrafico-afligem-favelas-pacificadas-do-rio-20111009.html $>$.

NOTÍCIAS R7 Record, 2012. Moradores contabilizam prejuizos após incêndio na favela do Moinho. Disponível em: < http://noticias.r7.com/sao- paulo/fotos/moradores-contabilizam-prejuizos-aposincendio-na-favela-do- moinho-20120917-15.html>.

O Globo, 2015. No 'tribunal' do tráfico da milícia, a tortura é punição rotineira. Disponível em: < http://oglobo.globo.com/rio/no-tribunal-do- trafico-da-milicia-tortura-punicao-rotineira-16743038>. 
PORTAL Afro, 2012. O surgimento das favelas no Brasil. Disponível em: $<$ http://portalafrobrasil.blogspot.com.br/2012/10/o-surgimento-das-favelas-no-brasil.html>.

REVISTA Marie Claire, 2012. Cabeças marcadas pelo tráfico: "código penal" de algumas favelas cariocas castiga mulheres raspando seus cabelos. Disponível em: $<$ http://revistamarieclaire.globo.com/Revista/Common/0,EMI313737-17737-1,00-

CABECAS+MARCADAS+PELO+TRAFICO+CODIGO+PENAL+DE+ALGUMAS

+FAVELAS+CARIOCAS+CAST.html>.

REVISTA Veja, 2015. Os traficantes e o império da lei nas favelas. Disponível em: < http://veja.abril.com.br/blog/cacador-de-mitos/economia/os-traficantes-e-o-imperio-da-lei-nasfavelas/>.

SANTOS, Boaventura de Sousa. Uma cartografia simbólica das representações sociais. Revista Crítica de Ciências Sociais, n. 24, p. 139-172, 1988.

UNITED Nations. World Economic and Social Survey 2013: Sustainable Development Challenges. New York: Department of Economic and Social Affairs of United Nations, 2013.

WEBER, Max. Três tipos puros de poder legítimo. Lisboa: Tribuna de História, 2005.

WOLKMER, Antônio Carlos. Pluralismo Jurídico: Fundamentos de uma nova cultura no direito. São Paulo: Editora Alfa Omega, 2001.

WOLKMER, Antonio Carlos. Pluralismo jurídico: nuevo marco emancipatorio en América Latina. Disponible em: $<$ http://bibliotecavirtual.clacso.org.ar/ar/libros/derecho/wolk.rtf $>$.

ZACCONE, Orlando. Indignos de vida: a forma jurídica da política de extermínio de inimigos na cidade do Rio de Janeiro. Rio de Janeiro: Editora Revan, 2015.

ZERO Hora, 2015. Chefe do crime e benfeitor: as duas faces de Xandi. Disponível em < http://zh.clicrbs.com.br/rs/noticia/2015/03/chefe-do-crime-e-benfeitor-as-duas-faces-de-xandi4712630.html>.

ZERO Hora, 2015. Como traficantes passaram de amigos a rivais em Porto Alegre. Disponível em: < http://zh.clicrbs.com.br/rs/noticias/noticia/2015/05/como-traficantes-passaram-de-amigos-a-rivaisem-porto-alegre-4756286.html>.

Recebido em: 25/08/2016

Aceito em: 27/08/2016 
A substituição indevida da ordem estatal por direitos inoficiais: da inefetividade dos estados sociais à emergência de pluralismos jurídicos questionáveis quanto a sua legitimidade

Revista da Faculdade de Direito da UFRGS, Porto Alegre, n. 34, p. 48-65, ago. 2016.

ISSN: 0104-6594 Site http://seer:ufrgs.br/revfacdir

Faculdade de Direito da UFRGS - Rua Riachuelo, 1317 - Centro - Porto Alegre - RS - Brasil

CEP - 90010-271 - Telefone: +55 5133083118 - Site http://www.ufrgs.br/direito/ 